\title{
Glutathione Is a Low-Affinity Substrate of the Human Sodium-Dependent Dicarboxylate Transporter
}

\author{
Lena Schorbach Wolfgang Krick Gerhard Burckhardt Birgitta C. Burckhardt \\ Institute of Systemic Physiology and Pathophysiology, University Medical Center Göttingen, Göttingen, Germany
}

\section{Key Words}

Detoxification · Glutathione · Redox status ·

Sodium-dependent dicaboxylate transporter 3 .

Thiol status

\begin{abstract}
Background/Aims: During a single pass through the kidneys, more than $80 \%$ of glutathione (GSH) is excreted, indicating not only glomerular filtration, but also tubular secretion. The first step in tubular secretion is the uptake of a substance across the basolateral membrane of proximal tubule cells by sodium-dependent and -independent transporters. Due to the dicarboxylate-like structure, we postulated that GSH uptake across the basolateral membrane is mediated by the sodium-dependent dicarboxylate transporter 3 (NaDC3). Methods: Tracer uptake and electrophysiologic measurements using a two-electrode voltage clamp device were performed in Xenopus laevis oocytes expressing the human (h) NaDC3. Results: Uptake of succinate, the reference substrate of hNaDC3, was inhibited by GSH in a dose-dependent manner with an $\mathrm{IC}_{50}$ of $1.88 \mathrm{~mm}$. GSH evoked potential-dependent inward currents, which were abolished under sodiumfree conditions. At $-60 \mathrm{mV}$, GSH currents showed saturation kinetics with a $\mathrm{K}_{\mathrm{M}}$ of $1.65 \mathrm{~mm}$. Conclusion: hNaDC3 present at the basolateral membrane of proximal tubule cells mediates sodium-dependent GSH uptake. The kinetic data show that $\mathrm{NaDC} 3$ is a low-affinity GSH transporter.
\end{abstract}

(c) 2013 S. Karger AG, Basel

\section{KARGER}

(C) 2013 S. Karger AG, Base

$1660-2137 / 13 / 1242-0001 \$ 38.00 / 0$

E-Mail karger@karger.com

www.karger.com/nep

\section{Introduction}

A number of studies have demonstrated the importance of reduced glutathione (GSH) in cell biology. GSH plays a critical role in protecting cells from oxidative stress and xenobiotics, as well as maintaining the thiol redox state, most notably in the central nervous system, but also in systems extracting numerous potentially toxic compounds from the body such as the liver and the kidneys [1-7].

The kidneys possess several unique properties and functions with respect to their handling of GSH. These include a high capacity for intracellular GSH synthesis from the precursor amino acids, glycine, cysteine and glutamate. These GSH precursors are derived not only from glomerular filtration and tubular reabsorption of the free amino acids, but also from degradation of the filtered dipeptides cysteinylglycine, CysGly, and $\gamma$-glutamylcysteine, $\gamma$ GluCys, by the $\gamma$-glutamyltransferase, $\gamma \mathrm{GT}$, at the luminal surface of proximal tubules. In addition, extraction of GSH from the blood appears to occur by sodiumindependent and sodium-dependent processes. Thus, the GSH concentration in proximal tubule cells is the result of intracellular synthesis and GSH uptake across the basolateral membrane [8-13].

Initial studies in basolateral membrane vesicles and isolated proximal tubular cells provided evidence for a role of specific transporters for GSH uptake across renal basolateral membranes. This evidence included inhibition 
of GSH transport by $p$-aminohippurate, $\mathrm{PAH}$, and probenecid, the reference substrate and inhibitor of organic anion transport, respectively. With the help of expression and homology cloning, several organic anion transporters (OATs) have been identified, and these transport or interact with a variety of structurally unrelated compounds [14-16]. Whereas transport of GSH by OAT3 present in NRK-52E cells seems possible [17], no interaction of GSH with either human OAT1 or OAT3 in stably transfected HEK293 cells could be demonstrated [18].

GSH uptake was sensitive to membrane potential changes and inhibited by dimethylsuccinate, an inhibitor of dicarboxylate transport [10, 19]. The involved transporter has since been identified as the high-affinity sodium-dependent dicarboxylate transporter 3 (NaDC3) which belongs to the SLC13 gene family [20, 21]. While two members of the SLC13 family (SLC13A1 and SLC13A4) transport anions such as sulfate and dioxyanions, the three other members (SLC13A2: NaDC1; SLC13A3: NaDC3, and SLC13A5: NaCT) transport diand tricarboxylates. Transcripts of $\mathrm{NaDC} 1, \mathrm{NaDC} 3$ and $\mathrm{NaCT}$ have been detected in the liver and the kidneys [22], where $\mathrm{NaDC} 1$ is present in the luminal and $\mathrm{NaDC} 3$ in the basolateral membrane. The purpose of the present study was to evaluate the possible interaction of GSH with the human (h)NaDC3 as an entry step for GSH into proximal tubule cells.

\section{Concise Methods}

In vitro Transcription of $h N a D C 3-c R N A$

Linearized plasmid DNA from hNaDC3 (GenBank Accession No. AF154121) was used as a template for cRNA synthesis. The plasmid was linearized with Not I and in vitro cRNA transcription was performed using the T7 mMessage mMaschine kit (Ambion, Austin, Tex., USA) according to the manufacturer's instructions. The resulting cRNA was suspended in purified, RNAse-free water to a final concentration of $1 \mu \mathrm{g} / \mu \mathrm{l}$.

\section{Solutions}

A standard oocyte Ringer solution (ORi) was used for oocyte preparation, storage, and for the uptake as well as the electrophysiological experiments. ORi contained (in $\mathrm{mM}$ ): $110 \mathrm{NaCl}, 3 \mathrm{KCl}$, $2 \mathrm{CaCl}_{2}$ and $5 \mathrm{HEPES} /$ Tris. Sodium-free conditions were achieved by replacing $\mathrm{NaCl}$ by $\mathrm{N}$-methyl-D-glucamine and $\mathrm{HCl}$. Succinate and reduced GSH were added to ORi in the concentrations indicated in the figure legends, and $\mathrm{pH}$ was always adjusted to $\mathrm{pH}$ 7.5. To avoid oxidation of GSH, all solutions containing GSH were prepared immediately before the experiments started (electrophysiologic studies) or dithiothreitol (DTT) was added to the incubation medium (tracer uptake experiments). All chemicals were purchased from Sigma-Aldrich (Taufkirchen, Germany) and AppliChem (Darmstadt, Germany).
Oocyte Preparation and Storage

Stage V and VI oocytes from Xenopus laevis (Nasco, Fort Atkinson, Wis., USA) were separated by an overnight treatment with collagenase (Typ CLS II; Biochrom, Berlin, Germany), subsequent washings in calcium-free ORi, and maintaining again in ORi with $2 \mathrm{mM}$ calcium. One day after removal from the frog, oocytes were injected with $23 \mathrm{nl}$ cRNA coding for hNaDC3, or an equivalent amount of water (mocks). After 3 days of incubation at $16-18^{\circ} \mathrm{C}$ in ORi supplemented with $50 \mu \mathrm{M}$ gentamycin and $2.5 \mathrm{mM}$ sodium pyruvate with daily medium changes, oocytes were used for tracer uptake or electrophysiologic studies.

\section{Transport Experiments}

Uptake of $\left[{ }^{14} \mathrm{C}\right]$ succinate $\left({ }^{14} \mathrm{C}[2,3]\right.$ succinic acid; Perkin Elmer, Rodgau, Germany) in hNaDC3-expressing oocytes was assayed at room temperature for $15 \mathrm{~min}$. Inhibition of succinate uptake by GSH was determined by simultaneous application of $18 \mu \mathrm{M}{ }^{14} \mathrm{C}$ succinate plus GSH in the presence and absence of DTT. Under all conditions, uptake was terminated by removal of the radioactive medium and immediate washings with $3 \times 1 \mathrm{ml}$ of ice-cold ORi. Oocytes were dissolved in $0.5 \mathrm{ml}$ of $1 \mathrm{~N} \mathrm{NaOH}$ by gently shaking for $120 \mathrm{~min}$ followed by neutralization with $0.5 \mathrm{ml}$ of $1 \mathrm{~N} \mathrm{HCl}$. The ${ }^{14} \mathrm{C}$-content was determined by liquid scintillation counting (Tricarb 2900TR; Perkin Elmer).

\section{Electrophysiologic Analysis}

Oocytes were placed into a $0.5-\mathrm{ml}$ chamber on the stage of an inverted microscope and impaled under direct view with borosilicate glass microelectrodes filled with $3 \mathrm{M} \mathrm{KCl}$ (BioMedical Instruments, Zöllnitz, Germany). Substrate-mediated currents were detected using a two-electrode voltage clamp device (OC725A; Warner, Hambden, Conn., USA) in the voltage clamp mode.

\section{Statistics and Calculations}

Data are provided as means \pm SEM. Paired Student's t test was used to show statistically significant differences of currents evoked by GSH and succinate in NaDC3-expressing oocytes or of succinate uptake in the absence and presence of GSH and/or DTT. Statistical significance was set at $\mathrm{p}<0.001$. The constant for half-maximal inhibition of succinate uptake by GSH $\left(\mathrm{IC}_{50}\right)$ and the Michaelis-Menten constant $\left(\mathrm{K}_{\mathrm{M}}\right)$ for GSH were calculated using SigmaPlot software (Systat Software, Point Richmond, Calif., USA).

\section{Results}

To avoid oxidation of reduced GSH to oxidized GSH during the uptake studies, DTT was added to the uptake media. Succinate uptake in the absence and presence of DTT (1 mM) was not statistically different. GSH (1 mM) inhibited succinate uptake in the absence and presence of DTT by $41.5 \pm 3.4$ and $41.8 \pm 5.1 \%$, respectively (fig. 1a). GSH inhibited succinate uptake in hNaDC3-expressing oocytes in a concentration-dependent manner (fig. 1b) with an $\mathrm{IC}_{50}$ of $1.88 \pm 0.55 \mathrm{~mm}$.

Figures $2 \mathrm{a}$ and $\mathrm{b}$ show original traces of currents evoked in oocytes injected with cRNA encoding for 


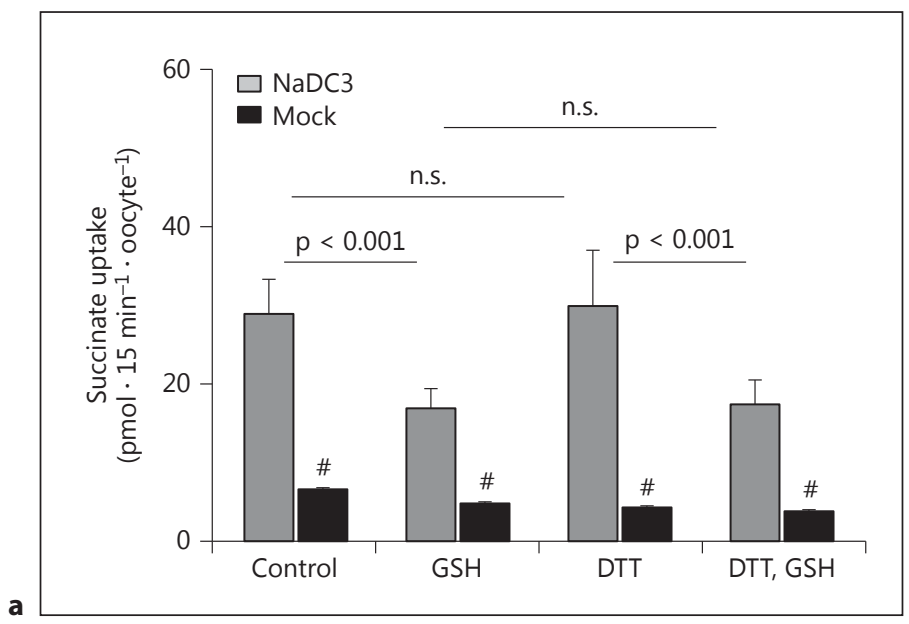

Fig. 1. Impact of GSH on succinate uptake. hNaDC3-expressing oocytes and mocks were incubated for $15 \mathrm{~min}$ in ORi containing $18 \mu \mathrm{M}\left[{ }^{14} \mathrm{C}\right]$-succinate in the absence and presence of $1 \mathrm{mM}$ DTT, $1 \mathrm{mM} \mathrm{GSH}$, and $1 \mathrm{mM}$ GSH plus $1 \mathrm{mM}$ DTT (a) or in the presence

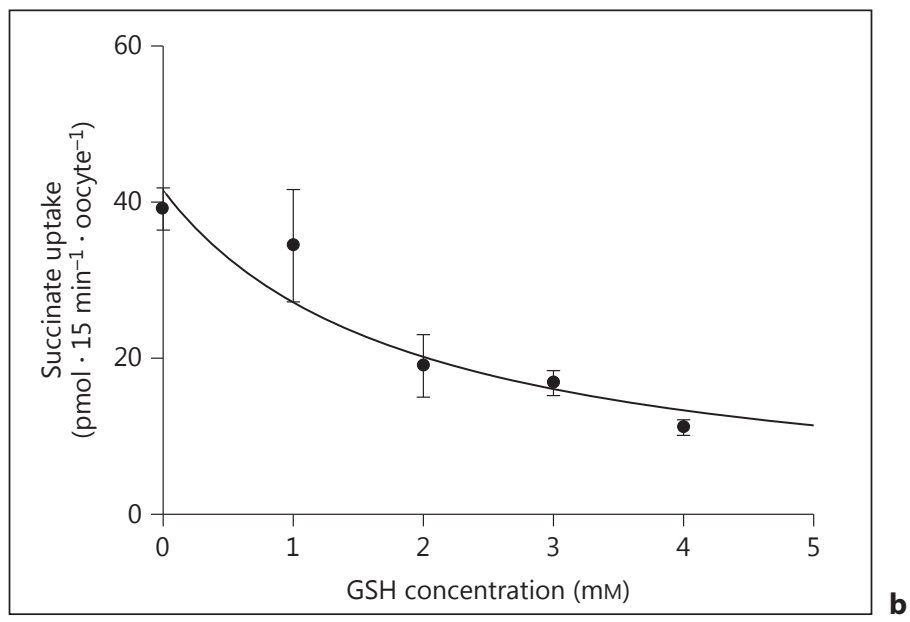

of increasing GSH concentrations to determine an $\mathrm{IC}_{50}(\mathbf{b})$. Data are from 3 experiments each with 8-10 oocytes per experimental condition. Statistical significance is indicated at $\mathrm{p}<0.001$; ${ }^{*}$ indicates no significance between mocks. n.s. $=$ Not significant.
Fig. 2. a Comparison of GSH-mediated currents in hNaDC3-expressing oocytes as well as in mocks at a clamp potential of -60 $\mathrm{mV}$. In these oocytes application of $5 \mathrm{~mm}$ succinate or GSH dissolved in ORi, pH 7.5, evoked substrate-associated currents as long as succinate or GSH were in the superfusate (black bars). b A summary of the results is presented, including 14 oocytes from 8 donors in hNaDC3-expressing oocytes and 5 oocytes from 4 donors in mocks.
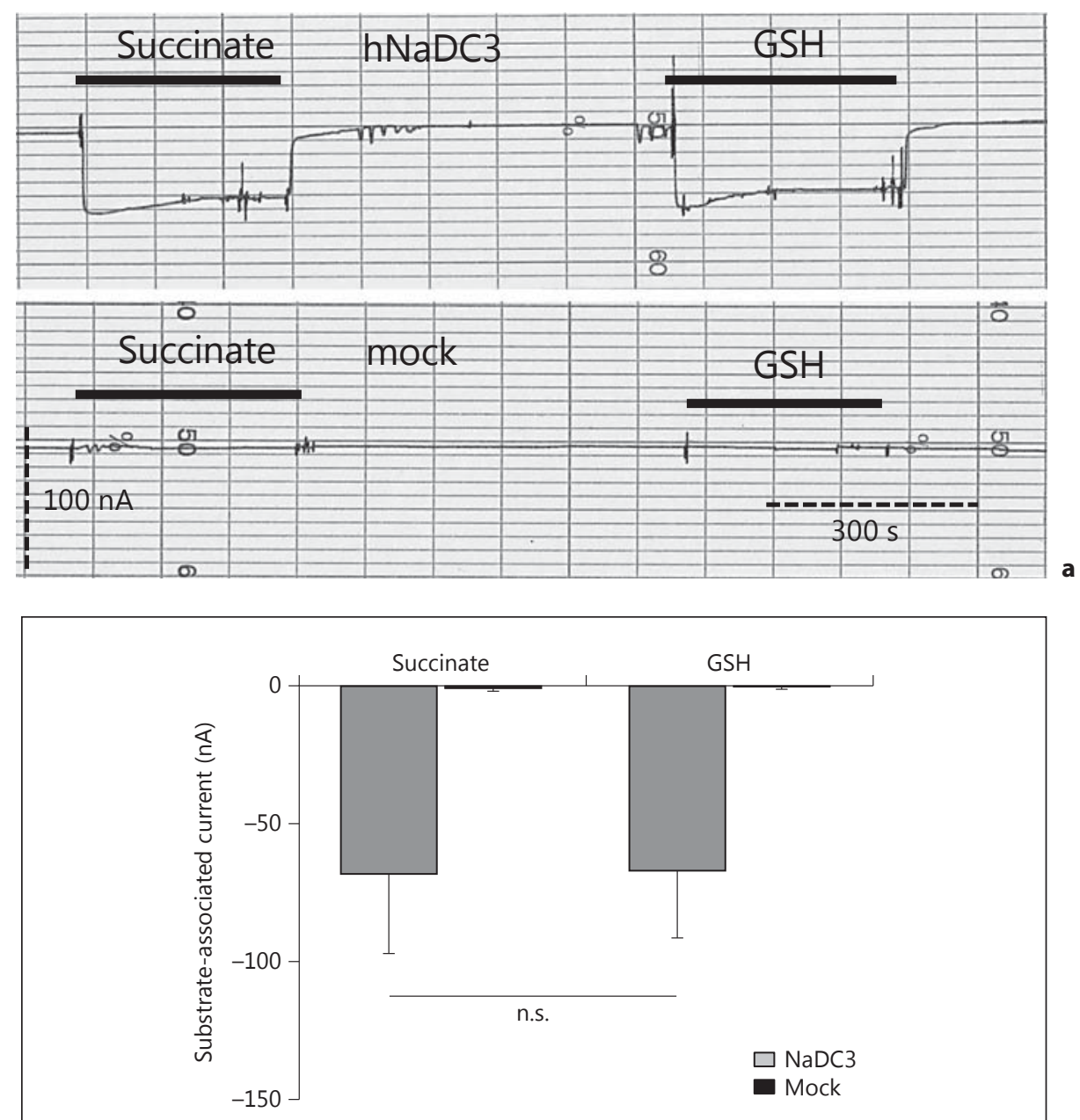

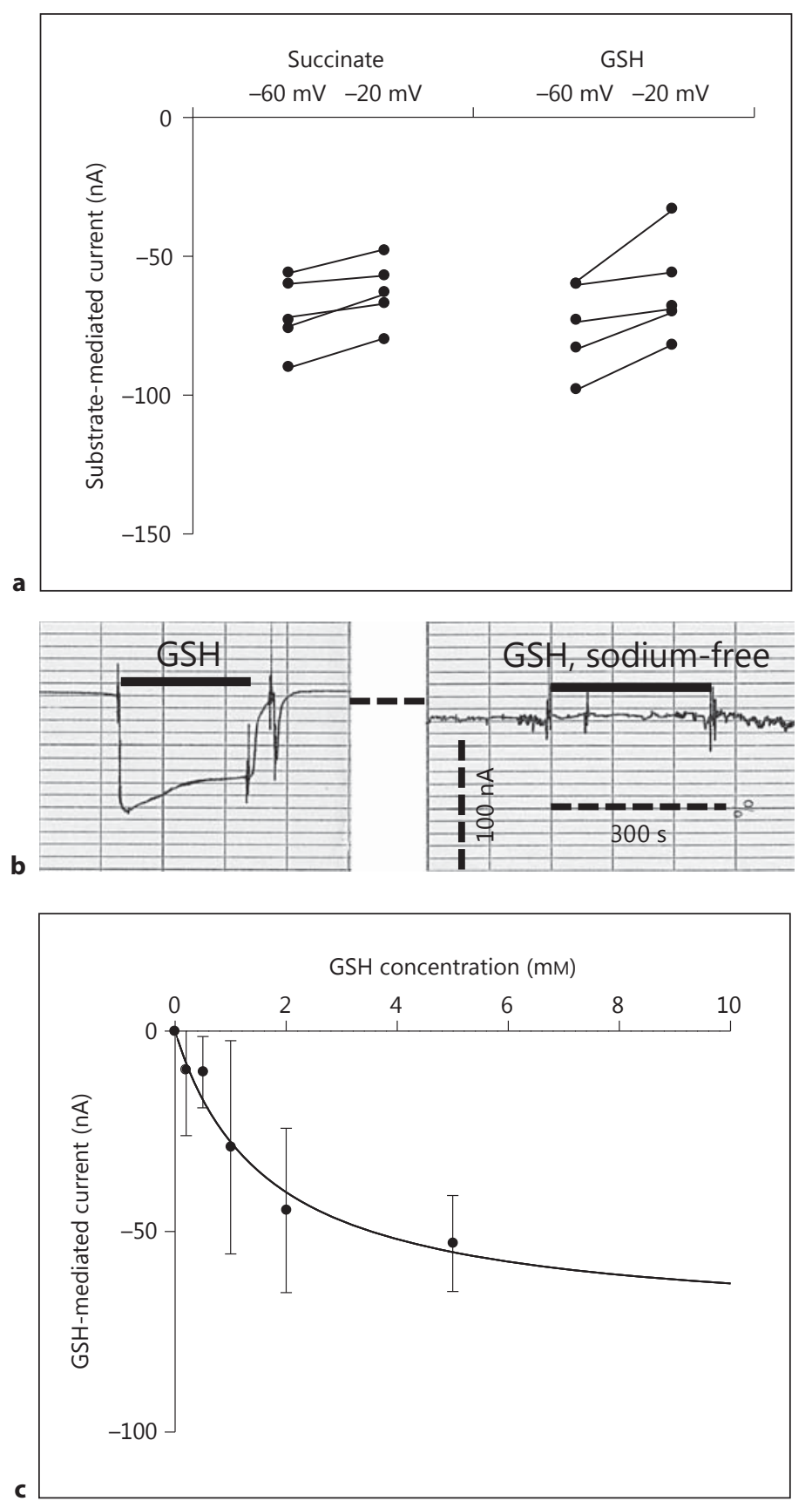

Fig. 3. Potential (a), sodium (b) and concentration (c) dependence of GSH-mediated currents. a Oocytes were first clamped at -60 $\mathrm{mV}$ and $5 \mathrm{mM}$ succinate dissolved in ORi, $\mathrm{pH} 7.5$, was applied to demonstrate successful expression. Afterwards, oocytes were clamped to $-20 \mathrm{mV}$ and again succinate was applied. The same potential protocol was used for GSH ( $5 \mathrm{~mm}$ dissolved in ORi, $\mathrm{pH}$ 7.5). The initial substrate-associated current amplitudes are plotted at the two clamp potentials. $\mathbf{b}$ The sodium dependence of the GSH-evoked current was investigated only at $-60 \mathrm{mV}$. The trace shows a representative example out of a total of 3 experiments. The concentration dependence was evaluated at $-60 \mathrm{mV}$ by subsequent application of the GSH concentrations at $\mathrm{pH}$ 7.5. The $\mathrm{K}_{\mathrm{M}}$ was calculated from 4 measurements.
$\mathrm{hNaDC} 3$ and in water-injected oocytes upon application of GSH. The reference substrate of $\mathrm{hNaDC} 3$, succinate, was included in the protocol to demonstrate sufficient expression. At $-60 \mathrm{mV}, \mathrm{GSH}$ and succinate (each $5 \mathrm{mM}$ ) produced inward currents in hNaDC3-expressing oocytes. Water-injected oocytes did not respond to succinate or GSH (fig. 2a). As measured in paired experiments (fig. $2 \mathrm{~b}$ ) on 14 oocytes from 8 donors, $5 \mathrm{~mm}$ succinate evoked currents of $-68.5 \pm 28.8 \mathrm{nA}$, and $5 \mathrm{mM} \mathrm{GSH}$ currents of $-67.4 \pm 24.3 \mathrm{nA}$. Succinate and GSH currents were not statistically different at the $\mathrm{p}<0.001$ level. Water-injected oocytes showed currents of $-1.2 \pm 1.1 \mathrm{nA}$ and $-0.6 \pm 1.0 \mathrm{nA}$, respectively (5 oocytes from 4 frogs).

In paired experiments, as observed on 5 oocytes from 4 donors, succinate- and GSH-dependent currents were first measured at a clamp potential of $-60 \mathrm{mV}$ and subsequently at $-20 \mathrm{mV}$. Succinate- and GSH-evoked currents declined upon depolarization (fig. 3a). GSH-dependent currents were abolished when sodium was replaced by $\mathrm{N}$ methyl-D-glucamine (fig. 3b). Water-injected oocytes did not show potential or sodium dependence (data not shown). Increasing concentrations of GSH evoked currents of increasing amplitude which tended to saturate at concentrations $>5 \mathrm{mM}$ (fig. 3c). Higher concentrations of GSH were not tested for possible nonspecific effects on membrane proteins. From these data a $\mathrm{K}_{\mathrm{M}}$ of $1.65 \pm 0.56$ $\mathrm{mM}$ and $\mathrm{I}_{\max }$ of $-73.3 \pm 10.6 \mathrm{nA}$ was calculated (4 oocytes from 4 donors).

\section{Discussion}

In its reduced form, GSH is the most abundant nonprotein thiol in mammalian cells and the prevalent low molecular weight peptide in eukaryotic cells. The intracellular concentration of GSH reflects a balance between synthesis, consumption due to detoxification reactions, and transport. Efflux occurs by members of the ATPbinding cassette domain family ( $\mathrm{ABC}$ transporters) and the organic anion-transporting polypeptide family, OATPs [2]. GSH uptake from the interstitial space into cells has been especially proposed for proximal tubule cells because more than $80 \%$ of the plasma GSH is extracted during a single pass through the kidneys [23].

GSH uptake into proximal tubule cells is an energetically uphill process. Not only a chemical gradient for GSH greater than two orders of magnitude, but also a cell membrane potential of more than $-60 \mathrm{mV}$ has to be overcome by the negatively charged GSH. Uptake against such unfavorable conditions can only occur when the 
transport of GSH is coupled to a surplus of transported sodium ions. In rat renal basolateral membrane vesicles sodium-dependent uptake of GSH has been demonstrated $[9,10]$. In the present study we tested whether $\mathrm{NaDC} 3$, an electrogenic transporter translocating three sodium ions and one divalent dicarboxylate into the cell, is responsible for GSH uptake.

For this purpose, $X$. laevis oocytes were injected with cRNA coding for hNaDC3. X. laevis oocytes are most suitable for these investigations because they possess only a limited ability to degrade GSH [24]; therefore, protection of GSH degradation by the use of acivicin is not necessary. To demonstrate an interaction of GSH with hNaDC3, these oocytes were investigated with electrophysiologic and tracer uptake studies. Electrophysiologic experiments have the advantage that transport of a substrate can be directly proven by detection of substrateassociated currents. In the presence of sodium, but not in its absence, inward currents due to GSH application were observed. As expected for an electrogenic transporter, GSH currents diminished in magnitude as the oocytes were depolarized. These observations are in agreement with previous data [10] on basolateral membrane vesicles.
Using valinomycin in the presence of intra- to extracellular potassium gradients, the same group demonstrated that negative membrane potentials stimulated GSH uptake, and positive ones inhibited it [10].

By application of increasing GSH concentrations, GSH-induced currents were saturated. From these data, a $\mathrm{K}_{\mathrm{M}}$ of $1.65 \mathrm{mM}$ was calculated, which is in good agreement with the $\mathrm{IC}_{50}$ of $1.88 \mathrm{mM}$ determined for the inhibition of succinate uptake by GSH. $\mathrm{K}_{\mathrm{M}}$ exceeds the plasma concentration of GSH (approx. $5 \mu \mathrm{M}$ ) by a factor of 330 and identifies GSH as a low-affinity substrate of hNaDC3.

In summary, we have identified $\mathrm{hNaDC} 3$ as the sodium-dependent GSH transporter present in the basolateral membrane of proximal tubule cells. Since $\mathrm{NaDC} 3$ is not only present in the kidneys, but also in astrocytes, the liver, and the cornea [25], and GSH serves multiple functions in health and disease, $\mathrm{NaDC} 3$ may also protect these organs from various toxins and oxidants.

\section{Acknowledgement}

This work was supported by a grant from the German Research Council to B.C.B. (BU998/5-1).

\section{References}

1 Ballatori N, Krance SM, Notenboom S, Shi S, Tieu K, Hammond CL: Glutathione dysregulation and the etiology and progression of human diseases. Biol Chem 2009; 390: 191-214.

-2 Ballatori N, Krance SM, Marchan R, Hammond CL: Plasma membrane glutathione transporters and their roles in cell physiology and pathophysiology. Mol Aspects Med 2009; 30: 1328.

3 Franco R, Schoeneveld OJ, Pappa A, Panayiotidis MI: The central role of glutathione in the pathophysiology of human disease. Arch Physiol Biochem 2007; 113:234-258.

4 Hammond CL, Lee TK, Ballatori N: Novel roles for glutathione in gene expression, cell death, and membrane transport of organic solutes. J Hepatol 2001;34:946-954.

5 Lash LH: Role of glutathione transport processes in kidney function. Toxicol App Pharmacol 2005;204:329-342.

6 Lash LH: Renal membrane transport of glutathione in toxicology and disease. Vet Pathol 2011; 48:408-419.

7 Ristoff E, Larsson A: Inborn errors in the metabolism of glutathione. Orph J Rare Dis 2007;2: 16.

8 Gukasyan HJ, Lee VHL, Simityan H, Kim K-J, Kannan R: Thermodynamic stoichiometry of $\mathrm{Na}^{+}$-coupled glutathione transport. Can J Physiol Pharmacol 2006; 84:1223-1227.

$\checkmark 9$ Lash LH, Jones DP: Transport of glutathione by renal basal-lateral membrane vesicles. Biochem Biophys Res Commun 1983;112:55-60.
10 Lash LH, Jones DP: Renal glutathione transport: characteristics of the sodium-dependent system in the basal-lateral membrane. J Biol Chem 1984. 259: 14508-14515.

11 Parks LD, Zalups RK, Bafuss DW: Luminal and basolateral membrane transport of glutathione in isolated perfused $S_{1}, S_{2}$, and $S_{3}$ segments of the rabbit proximal tubule. J Am Soc Nephrol 2000; 11:1008-1015

12 Rankin BB, Curthoys NP: Evidence for the renal paratubular transport of glutathione. FEBS Lett 1982;147:193-196.

13 Rankin BB, Wells W, Curthoys NP: Rat renal peritubular transport and metabolism of plasma $\left[{ }^{35}\right.$ S]glutathione. Am J Physiol Renal Physiol 1985;249:F198-F204.

14 Burckhardt G: Drug transport by organic anion transporters (OATs). Pharmacol Ther 2012;136 106-130.

15 Koepsell H: The SLC22 family with transporters of organic cations, anions and zwitterions. Mol Aspects Med 2013;34:413-435.

16 VanWert AL, Gionfriddo MR, Sweet DH: Organic anion transporters: discovery, pharmacology, regulation and roles in pathophysiology. Biopharm Drug Dispos 2010;31:1-71.

17 Lash LH, Putt DA, Feng X, Mathely LH: Role of rat organic anion transporter 3 (Oat3) in the renal basolateral transport of glutathione. Chem Biol Interact 2007; 170: 124-134.

18 Hagos Y, Burckhardt G, Burckhardt BC: Human organic anion transporter OAT1 is not responsible for glutathione transport but mediates transport of glutamate derivatives. Am J Physiol Renal Physiol 2013;304:F403-F409.

19 Lash LH, Putt DA: Renal cellular transport of exogenous glutathione: heterogeneity at physiological and pharmacological concentrations. Biochem Pharmacol 1999; 58:897-907.

20 Bergeron MJ, Clemencon B, Hediger MA, Markovich D: SLC13 family of $\mathrm{Na}^{+}$-coupled di- and tricarboxylate/sulfate transporters. Mol Aspects Med 2013;34:299-312.

21 Pajor AM: Molecular properties of the SLC13 family of dicarboxylate and sulfate transporters. Pflügers Arch 2006;451:597-605.

22 Yodoya E, Wada M, Shimada A, Katsukawa H, Okada N, Yamamoto A, Ganapathy V, Fujita T: Functional and molecular identification of sodium-coupled dicarboxylate transporters in rat primary cultured cerebrocortical astrocytes and neurons. J Neurochem 2006;97:162-173.

23 Häberle D, Wahlländer A, Sies H: Assessment of the kidney function in maintenance of plasma glutathione concentration and redox state in anaesthetized rats. FEBS Lett 1979; 108:335-340.

24 Ballatori N, Wang W, Li L, Truong AT: An endogenous ATP-sensitive glutathione S-conjugate efflux mechanism in Xenopus laevis oocytes. Am J Physiol Integrative Comp Physiol 1996; 270:R1156-R1162.

25 Li B, Lee MS, Lee RS, Donaldson PJ, Lim JC: Characterization of glutathione uptake, synthesis, and efflux pathways in the epithelium and endothelium of the rat cornea. Cornea 2012;31: 1304-1312. 